\title{
Metastatic Genitourinary System Carcinoma
}

National Cancer Institute

\section{Source}

National Cancer Institute. Metastatic Genitourinary System Carcinoma. NCI Thesaurus.

Code C146893.

A carcinoma that arises from the genitourinary system and has metastasized to other anatomic sites. 